\title{
Characterization of $\mathrm{miR}-218 / 322-$ Stxbp1 pathway in the process of insulin secretion
}

\author{
Hongmei Lang', Zhihua Ai', Zhiqing You', Yong Wan', Wei Guo', Jie Xiao ${ }^{2}$ \\ and Xiaolan Jin ${ }^{1}$
}

Correspondence should be addressed to $X$ Jin

Email

williamsjin@sinacom
Journal of Molecular

Endocrinology

(2015) 54, 65-73

\section{Introduction}

MicroRNAs (miRNAs) are a novel family of small noncoding RNAs, typically 22 nucleotides in length. They negatively regulate gene expression by base pairing to complementary sites on the $3^{\prime}$ UTR of target mRNAs, leading to translation repression or mRNA degradation. So far, miRNAs have been found to be involved in a wide range of biological and pathological processes, including cell apoptosis, migration, metabolism, immune response, aging, and organic development (Pelaez \& Carthew 2012, Zhang et al. 2015).

Type 2 diabetes (T2D) is characterized by reduced insulin secretion from pancreatic $\beta$-cells and insulin resistance at the target cells, which result in increased blood glucose levels (Kahn 2001). It has been reported that impaired insulin secretion has already occurred before the onset of T2D, indicating that the insulinsecretion processes are crucial during the development of the disease (Hosker et al. 1989, Del Prato \& Tiengo 2001).

Syntaxin-binding protein 1 (Stxbp1 or Munc18-1) modulates the folded conformation of syntaxin $1 \mathrm{~A}$, which acts as an important regulator in intracellular vesicle trafficking (Dong et al. 2007). Although the interaction of Stxbp1 and syntaxin 1A plays a key role

Published by Bioscientifica Ltd. 
in the process of insulin secretion, the upstream regulators of Stxbp1 remain undetermined.

miR-218 has been reported to be implicated in cancer cell proliferation and migration (Xiao et al. 2014), while miR-322 regulates cell cycle quiescence and cell differentiation in muscle cells (Sarkar et al. 2010). However, few studies have been focused on the role of miR-218 and miR-322 in $\beta$-cell function.

In this study, we first assessed the expression of Stxbp1 and its predicted pairing miRNAs in isolated islets treated with high levels of glucose for a short period. Stxbp1 was found to be significantly upregulated, while two of the screened miRNAs: miR-218 and miR-322 showed the opposite tendency. The subsequent luciferase assays confirmed that miR-218 and miR-322 directly interact with $3^{\prime} \mathrm{UTR}$ of Stxbp1; the overexpression of the two miRNAs in islet cell lines leads to a sharp decrease in expression of Stxbp1 and insulin secretion. The mechanism by which miRNAs regulate expression of Stxbp1 in islets exposed for long periods to high levels of glucose, known as glucolipotoxic, was also investigated in this study. To conclude, we identified miR-218/322Stxbp1-insulin as an important pathway in $\beta$-cell function.

\section{Material and methods}

\section{Animal preparation}

Male C57BL/6J mice (Mus musculus) were housed in a pathogen-free animal facility with access to water and food and allowed to eat and drink ad libitum. All of the animals were subject to controlled temperature $\left(22 \pm 1^{\circ} \mathrm{C}\right)$ and lighting (lights on 0600-1800 h). All of the experimental procedures were performed in accordance with protocols approved by the Institutional Animal Care and Research Advisory Committee.

\section{Isolation of islets from mouse pancreata}

Islets were isolated as described previously (Neuman et al. 2014). Mice were anesthetized by i.p. injection of sodium pentobarbital. Pancreatic islets were then isolated by injection of $500 \mathrm{U} / \mathrm{ml}$ of collagenase solution into the pancreatic duct followed by digestion at $37^{\circ} \mathrm{C}$ for $28 \mathrm{~min}$ with mild shaking. The islets were washed several times with D-Hank's solution $(136 \mathrm{mM} \mathrm{NaCl}, 0.53 \mathrm{mM} \mathrm{KCl}$, $4.2 \mathrm{mM} \quad \mathrm{NaHCO}_{3}, \quad 0.44 \mathrm{mM} \quad \mathrm{KH}_{2} \mathrm{PO}_{4}, \quad 0.385 \mathrm{mM}$ $\mathrm{Na}_{2} \mathrm{HPO}_{4}$ ), separated from acinar cells on a discontinuous Ficoll 400 gradient, viewed under a dissecting microscope, and hand-selected. Finally, the islets were collected and transferred into RPMI1640 medium containing 10\% fetal bovine serum (FBS).

The islets were cultured at $37^{\circ} \mathrm{C}$ in a humidified atmosphere containing 5\% $\mathrm{CO}_{2} / 95 \%$ air for $12 \mathrm{~h}$ (primary culture) for removal of exocrine and other tissues. Subsequently, islets were moved in to DMEM containing $5 / 25 \mathrm{mM}$ glucose and 10\% insulin-free FBS for insulin secretion studies (Zhang et al. 2001).

\section{PCR analysis}

Assays to quantify mature miRNAs were conducted as described previously (Chen et al. 2005). Total RNA was extracted from the cultured cells using TRIzol Reagent (Invitrogen) according to the manufacturer's instructions. PCR products of Stxbp1 mRNA were analyzed by agarose electrophoresis, and mRNA levels were further verified by RT-qPCR using subGreen.

In this study, miRNA expression in cells and islets was normalized to U6 snRNA (Schmittgen et al. 2004), and mRNA expression was normalized to Gapdh. The relative amount of each gene to internal control was calculated by using the equation $2^{-\Delta \mathrm{C}_{\mathrm{q}}}$, in which $\Delta \mathrm{Cq}=\mathrm{C}_{\mathrm{q} \text { gene }}-\mathrm{C}_{\mathrm{q} \text { control. }}$. Primers for Stxbp1 and Gapdh were as follows: 5'-CATGAGAGCCATTGTCCCCA-3' (Stxbp1, sense); 5'-AGTGCTTTGTATCCAGCTTGTC-3' (Stxbp1, antisense); 5'-AGAAGGCTGGGGCTCATTTG-3' (Gapdh, sense); 5'-AGGGGCCATCCACAGTCTTC-3' (Gapdh, antisense).

\section{Cell culture}

MIN6 cells were routinely maintained in 1640 medium supplemented with 20\% FBS, $1 \%$ glutamine, $1 \% \beta$-mercaptoethanol, and $10 \mathrm{mM}$ HEPES. The cells were cultured at $37{ }^{\circ} \mathrm{C}$ with $5 \% \mathrm{CO}_{2}$.

\section{The miRNA target prediction}

The miRNA target prediction and analysis were performed with the algorithms from TargetScan (http:// www.targetscan.org/) PicTar (http://pictar.mdc-berlin.de/) and miRanda (http://www.microrna.org/).

\section{MIN6 insulin secretion assay}

To determine the insulin secretion of MIN6 cells, cells were cultured in 96-well plates ( 40000 cells/well) for $48 \mathrm{~h}$. Then the medium was removed and cells were washed twice with glucose-free Krebs $(\mathrm{NaCl} 119 \mathrm{mM}, \mathrm{KCl}$ $4.74 \mathrm{mM}, \mathrm{CaCl}_{2} 2.54 \mathrm{mM}, \mathrm{MgCl}_{2} 1.19 \mathrm{mM}, \mathrm{KH}_{2} \mathrm{PO}_{4}$

Published by Bioscientifica Ltd 
$1.19 \mathrm{mM}, \mathrm{NaHCO}_{3} 25 \mathrm{mM}$, and HEPES (pH 7.4) $10 \mathrm{mM}$ ) containing $0.05 \%$ insulin-free BSA. An aliquot of $100 \mu \mathrm{l}$ of the above Krebs solution containing the desired amount of glucose was added to each well and cells were further cultured for $1 \mathrm{~h}$.

\section{Determination of insulin concentration}

Insulin concentrations in the medium were assessed, using mouse insulin as a standard, with a Rat/Mouse Insulin ELISA Kit (EMD Millipore (Billerica, MA, USA), catalog number: EZRMI-13K). In brief, samples were added into a 96-well plate with the rat/mouse insulin antibody at the bottom. To each sample, $20 \mu \mathrm{l}$ assay buffer, $10 \mu \mathrm{l}$ rat insulin standards/medium, and $80 \mu$ detection antibody was added. Subsequently, $100 \mu \mathrm{l}$ enzyme buffer, followed by $100 \mu \mathrm{l}$ substrate solution buffer, was added to each well. After a final stop solution was added, the insulin content was determined by reading the absorbance at $450 \mathrm{~nm}$.

\section{Cell transfections}

MIN6 cells were seeded on six-well plates and were transfected by using Lipofectamine 2000 (Invitrogen) according to the manufacturer's instructions. For each well, equal doses (100 nmol) of miRNA mimics, inhibitors, siRNAs, or scrambled negative control RNA were used. The cells were harvested at $24 \mathrm{~h}$ after transfection for real-time PCR analysis and western blotting.

\section{siRNA interference assay}

Three sequences from the coding region of mouse Stxbp1 were designed and synthesized by Invitrogen. A scrambled siRNA (Stealth RNAi Negative Control Kit, Invitrogen) was used as a negative control. Sequences of the Stxbp1 siRNAs were as follows: 5'-UAUCCUCCACAAUUGUGAUGCCCUC-3' (sense) and 5'-GAGGGCAUCACAAUUGUGGAGGAUA-3' (antisense).

\section{Plasmid construction and luciferase assay}

The entire 3'UTR of Stxbp1 was synthesized and inserted into a p-MIR-report plasmid (Ambion, GenePharm, Shanhai, China). A plasmid with a mutated Stxbp1 $3^{\prime}$ UTR was also constructed using the same method. For luciferase reporter assays, $2 \mu \mathrm{g}$ of firefly luciferase reporter plasmid, $2 \mu \mathrm{g}$ of $\beta$-galactosidase expression vector (Ambion), and equal amounts (200 pmol) of mimics, inhibitors, or scrambled negative control RNA were transfected into cells in six-well plates. The $\beta$-galactosidase vector was used as a transfection control. At $24 \mathrm{~h}$ after transfection, cells were assayed using luciferase assay kits (Promega).

\section{Immunofluorescence}

MIN6 cells were briefly washed twice with cold PBS, and then fixed in $4 \%$ paraformaldehyde for $10 \mathrm{~min}$ at RT. After fixation, the cells were washed with PBS $(3 \times 5 \mathrm{~min}, \mathrm{RT})$, and then permeabilized and blocked using $2 \%$ BSA (Sigma-Aldrich) and $0.05 \%$ Triton X-100 in PBS for $1 \mathrm{~h}$ at RT. Next, the cells were incubated with primary antibody (STXBP1, Santa Cruz, 1:500) in 2\% BSA/PBS in a humidified chamber overnight at $4{ }^{\circ} \mathrm{C}$, and then rinsed in PBS $(3 \times 5 \mathrm{~min}, \mathrm{RT})$. The cells were then incubated in secondary fluorescent antibodies (Invitrogen) in $2 \%$ BSA/PBS in a light-proof container for $1 \mathrm{~h}$ at RT. Finally, the cells were stained with DAPI and visualized using a fluorescence microscope.

\section{Western blotting analysis}

The STXBP1 expression was assessed by western blotting analysis and samples were normalized to GAPDH. Protein extraction was blocked with PBS-5\% fat-free dried milk at room temperature for $1 \mathrm{~h}$ and incubated at $4{ }^{\circ} \mathrm{C}$ for overnight with anti-STXBP1 (1:1000, Santa Cruz), antisyntaxin (1:1000, Santa Cruz), and anti-GAPDH (1:2000, Santa Cruz) antibodies respectively.

\section{Statistical analyses}

All data were were representative of at least three independent experiments. Data were expressed as mean \pm s.D. of three separate experiments. Statistical significance was considered at $P<0.05$ using the Student's $t$-test. In this study, '*' indicates ' $P<0.05$ ', and '**' indicates ' $P<0.01$ '.

\section{Results}

\section{Glucose-stimulated expression of Stxbp1 and insulin secretion}

High levels of glucose are well known to stimulate insulin synthesis and secretion, and the expression of the related proteins in this process usually shows a significant variation (Sun et al. 2011, Shantikumar et al. 2012). In this study, we first checked the expression of Stxbp1 and insulin secretion in isolated mouse islets cultured in

Published by Bioscientifica Ltd. 
media containing 5 or $25 \mathrm{mM}$ glucose (high glucose). High levels of glucose enhanced expression of Stxbp1 gradually within $1 \mathrm{~h}$ (Fig. 1A), while the Stxpp1 mRNA showed only a slight increase (Fig. 1C and Supplementary Figure S1, see section on supplementary data given at the end of this article). Meanwhile, insulin secretion was used to evaluate the function of $\beta$-cells. As expected, insulin secretion was increased under the influence of high levels of glucose (Fig. 1B).

The result confirmed that $S t x b p 1$ is an important positive regulator in the insulin secretion process, and also implied that Stxbp1 expression may be regulated by miRNAs.

\section{The expression of Stxbp1-related miRNAs in islets}

Rapid insulin secretion induced by glucose is partly regulated by autocrine factors, and miRNAs may play an important role in this process (Fred et al. 2010). A list of potential miRNAs that regulate expression of Stxbp1 are shown in Fig. 2A. To clarify whether the promotion of the expression of Stxbp1 was associated with miRNAs, we screened all the predicted miRNAs by qPCR, and found that miR-218 and miR-322 were clearly decreased
A
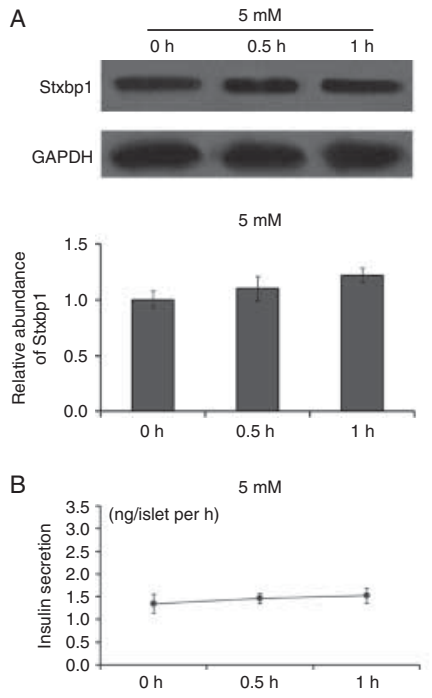

C

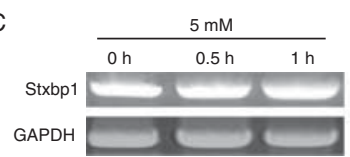

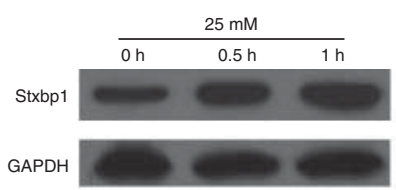
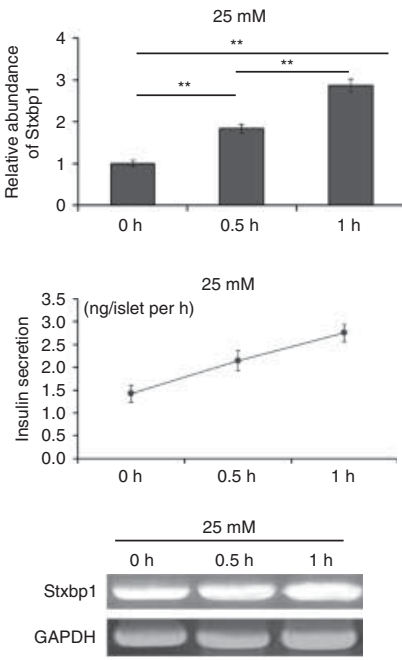

Figure 1

The expression of Stxbp 1 during the process of rapid insulin secretion. ( $A$ and $B$ ) The expression of Stxbp1 protein and insulin secretion in islets exposed to $5 \mathrm{mM}(\mathrm{A})$ or $25 \mathrm{mM}$ (B) glucose for 0.5 and $1 \mathrm{~h}$. (C) The mRNA levels of Stxbp1 during the process of rapid insulin secretion. Values are mean \pm s.E.M. $(n=3), * * P<0.01$

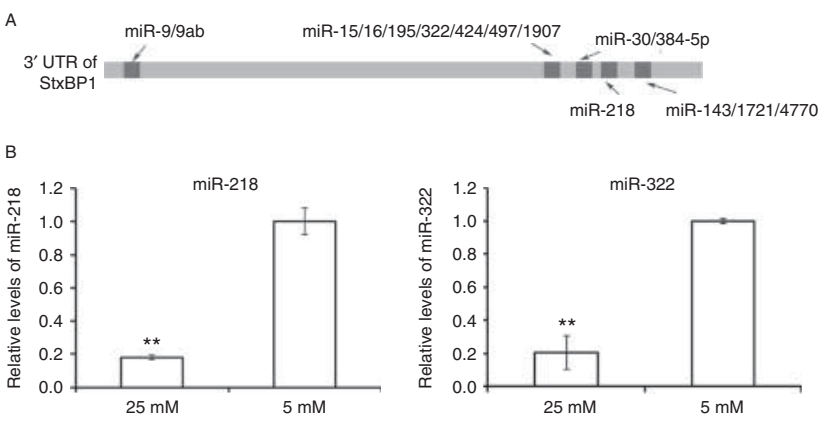

Figure 2

Relative levels of miR-218 and miR-322 in islets treated for a short period with high levels of glucose. (A) Bioinformatic analysis of potential pairing miRNAs of Stxbp1. (B) Relative levels of miR-218 (left chart) and miR-322 (right chart) in islets cultured for $1 \mathrm{~h}$ in the medium containing 5 and $25 \mathrm{mM}$ glucose $(n=3, * * P<0.01)$.

(Table 1). The observation indicated that miR-218 and miR-322 were involved in rapid glucose-stimulated insulin secretion (GSIS) though regulation of the expression of Stxbp1.

\section{Stxbp1 is a direct target of miR-218 and miR-322}

The expression levels and the computational prediction alone cannot provide direct evidence of the interaction between miRNAs and the target. Thus a luciferase assay was performed to evaluate the association. As is shown in Fig. 3A, the target region in the $3^{\prime}$ UTR of Stxbp1 was conserved among humans, mice and rats. Co-transfection of miR-218 mimics with the reporter plasmid containing WT Stxbp1 $3^{\prime}$ UTR sequence into 293T HEK cells resulted in a 50\% reduction in the luciferase signal, and miR-322 mimics decreased the relative luciferase activity to 40\% (Fig. 3B). However, the interaction was lost when the plasmid with a mutated sequence was used instead (Fig. 3C).

To verify the specific interaction between miR218/322 and Stxbp1 mRNA, another predicted miRNA was selected as a negative control. Figure 3D showed that the overexpression of miR-195 in HEK293 cells did not change the relative luciferase activity in both the WT group and the mutant group. A similar result was observed when miR-195 was inhibited in cells.

These results indicate that miR-218 and miR-195 directly target the 3'UTR of Stxbp1 mRNA.

\section{Downregulation of Stxbp1 by miR-218 and miR-322}

To study the biological role of miR-218 and miR-322 in $\beta$-cell function, MIN6 cells were transfected with mimics

Published by Bioscientifica Ltd 
Table 1 The screening of Stxbp1-related miRNAs in islets treated for a short period with high levels of glucose

\begin{tabular}{|c|c|c|c|}
\hline \multirow[b]{2}{*}{ miRNAs } & \multicolumn{2}{|c|}{ Glucose } & \multirow[b]{2}{*}{$P$ value } \\
\hline & $5 \mathrm{mM}$ & $25 \mathrm{mM}$ & \\
\hline miR-9 & 1 & 0.95 & 0.43 \\
\hline $\operatorname{miR}-15$ & 1 & 0.94 & 0.46 \\
\hline miR-16 & 1 & 0.89 & 0.34 \\
\hline miR-195 & 1 & 1.06 & 0.33 \\
\hline miR-322 & 1 & 0.21 & $<0.01$ \\
\hline miR-424 & 1 & 1.1 & 0.36 \\
\hline miR-497 & 1 & 1.07 & 0.31 \\
\hline miR-30 & 1 & 1.03 & 0.38 \\
\hline miR-384-5p & 1 & 0.87 & 0.26 \\
\hline miR-218 & 1 & 0.18 & $<0.01$ \\
\hline miR-143 & 1 & 0.92 & 0.29 \\
\hline
\end{tabular}

and inhibitors of the two miRNAs. The levels of miRNA were determined by real-time quantitative PCR analysis. The relative levels of the two miRNAs were significantly increased after transfection with mimics (Fig. 4A), while they declined when cells were transfected with inhibitors (Fig. 4C). We assessed the expression of Stxbp1 by western blotting assays at $24 \mathrm{~h}$ post-transfection. The expression levels of the STXBP1 protein were significantly reduced by the introduction of miR-218 and miR-322, whereas cells transfected with mimic control maintained a considerable amount of STXBP1 protein (Fig. 4B); in contrast, the inhibitors increased the relative expression levels of STXBP1 protein in MIN6 cells (Fig. 4D). These results indicate that miR-218 and miR-322 negatively regulate the expression of STXBP1 protein.

\section{Roles of miR-218, miR-322, and Stxbp1 in rapid insulin secretion}

To investigate the effects on insulin secretion of miR-218 and miR-322 targeting Stxbp1, MIN6 cells were transfected with miRNA mimics, inhibitors, or siRNA against Stxbp1 and analyzed for changes in insulin secretion though ELISA assays. The cells transfected with ncRNA or control siRNA served as controls. Efficient interference with Stxbp1 expression is shown in Fig. 4B and D.

As shown in Fig. 4E, the insulin secretion rate of MIN6 cells transfected with miRNA mimics was clearly decreased, and cells seemed insensitive to the glucose gradients. While MIN6 cells with blocking of miR-218 and miR-322 displayed a higher rate of insulin secretion compared with the controls (Fig. 4F). The knockdown of Stxpp1 by its siRNA also leads to a complete inhibition of insulin secretion (Fig. 4E).
Taken together, these results indicated that miR-218 and miR-322 negatively regulate insulin secretion from $\beta$-cells through silencing Stxbp1 expression.

\section{Role of miR-218, miR-322, and Stxbp1 in glucolipotoxicity}

Long-term exposure to high levels of glucose leads to the functional breakdown of islets, which is known as glucolipotoxicity, study of the mechanism of glucolipotoxicity in $\beta$-cells may provide a better understanding of

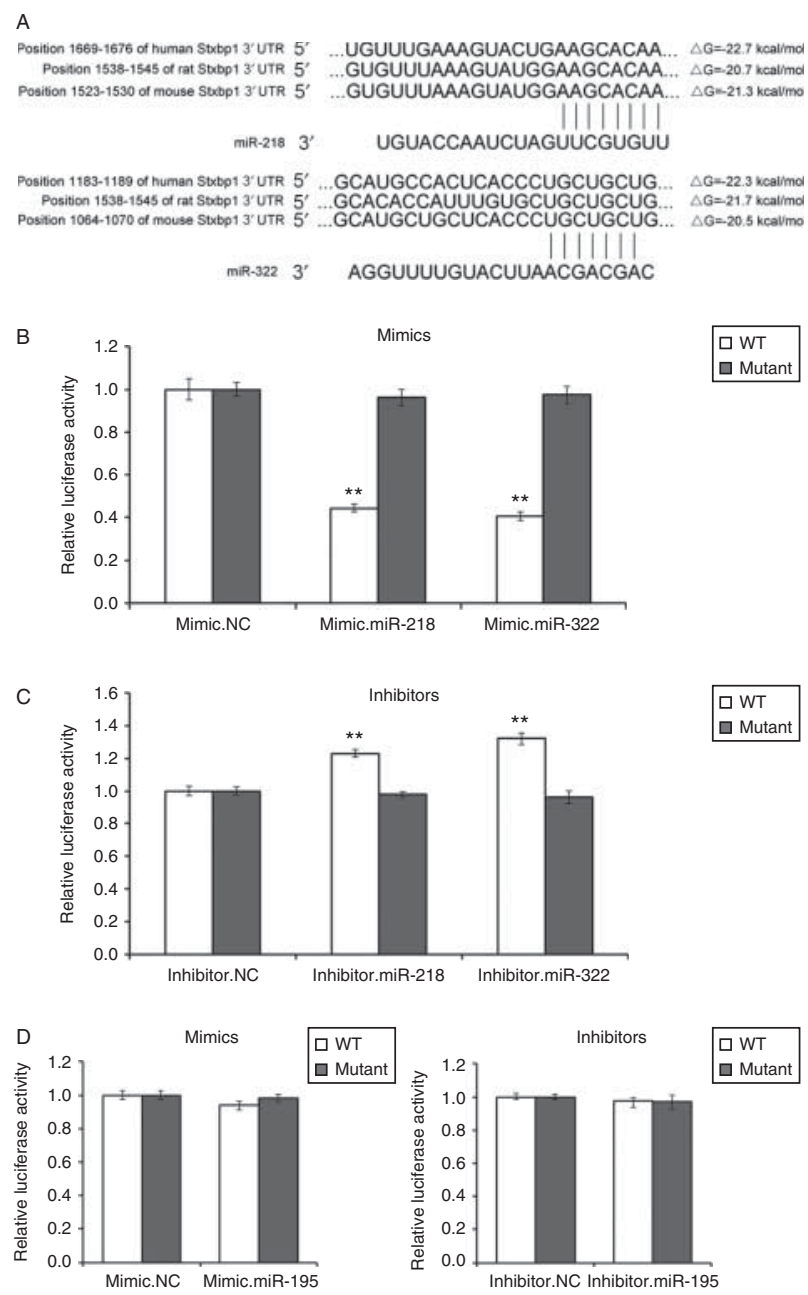

Figure 3

Identification of Stxbp 1 as the direct target of miR-218 and miR-322 by luciferase assays. (A) Schematic description of the hypothetical duplexes formed by interactions between miR-218, miR-322, and the $3^{\prime}$ UTR of Stxbp1. (B) Direct recognition of the Stxbp1 3'UTR by miR-218 and miR-322. (mean \pm S.E.M. $(n=3), * * P<0.01)$. (C) Firefly luciferase reporters containing either WT or mutant Stxbp1 3'UTR were co-transfected into A549 cells with scrambled non-coding RNA (NC) miRNA mimics, or miRNA inhibitors. At $24 \mathrm{~h}$ post-transfection, cells were assayed using luciferase assay kits $(n=3)$. (D) Relative luciferase levels for the Stxbp1 3'UTR with overexpression or inhibiton of miR-195 in HEK293 cells $(n=3)$.

Published by Bioscientifica Ltd. 

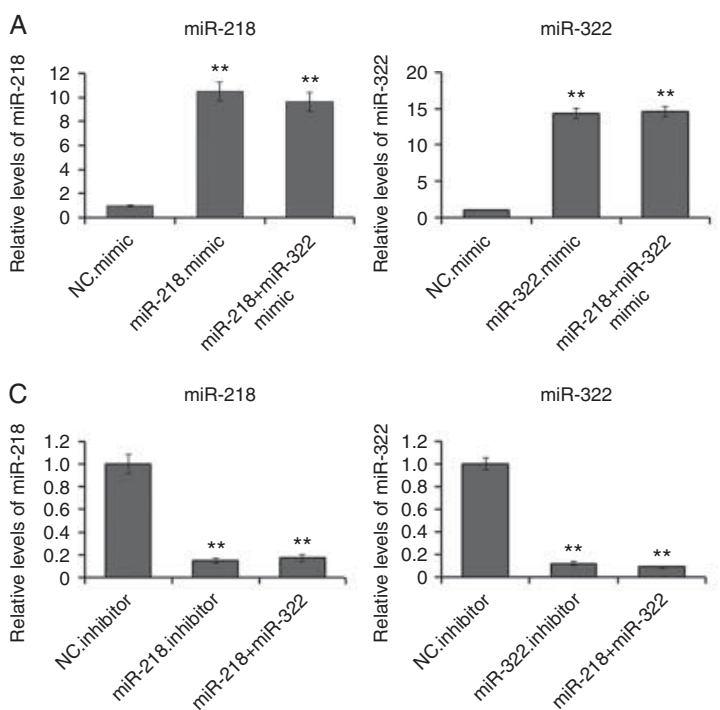

$\mathrm{E}$

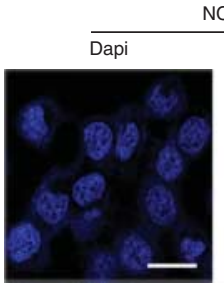

NC.mimic
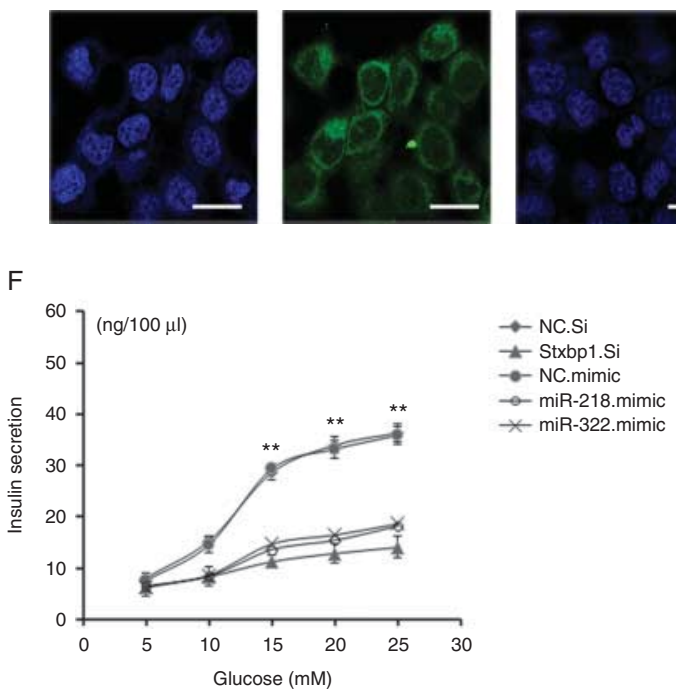

Figure 4

The role of miR-218 and miR-322 co-targeting Stxbp1 in the process of rapid insulin secretion. (A) Relative levels of miR-218 and miR-322 in MIN6 cells transfected with corresponding mimics. MIN6 cells were transfected with mimics of miR-218 or miR-322, or a mix of mimics of the two miRNAs, and cells were harvested after $24 \mathrm{~h}$ of incubation. The miRNA expression was assessed using quantitative PCR. Values are mean \pm s.E.M. $(n=3)$, $* * P<0.01$. (B) Western blotting analysis of expression of Stbxp1 in MIN6 cells under the influence of siRNA and miRNA mimics. (C) Relative levels of

development of T2D (Melloul et al. 1993). In this study, we proved that STXBP1 protein was decreased by nearly $80 \%$ in islets exposed to high levels of glucose for $72 \mathrm{~h}$ (Fig. 5A), while expression of Stxbp1 was constant in islets exposed to $5 \mathrm{mM}$ glucose (Fig. 5B). To determine whether miRNAs were implicated in this process, we also checked the mRNA levels. The Stxbp1 mRNA showed only a slight decrease in
B

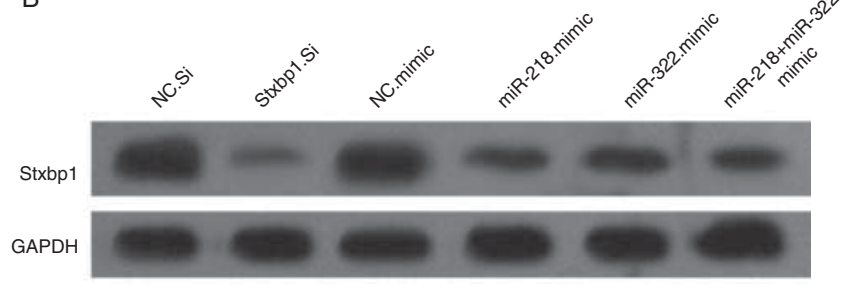

D
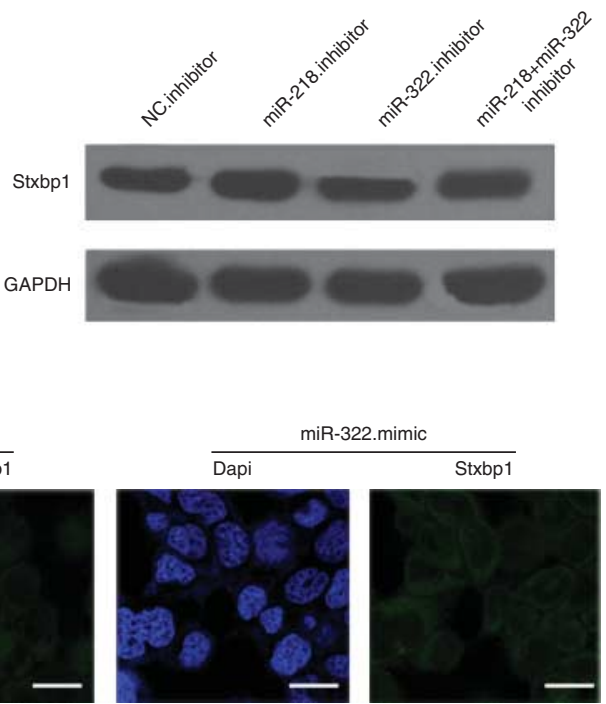

G

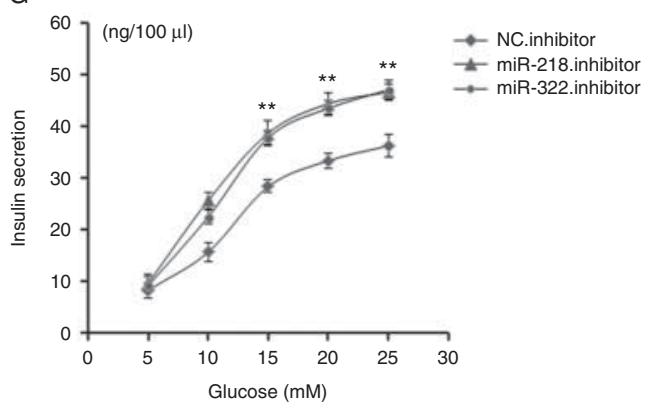

miR-218 and miR-322 in MIN6 cells transfected with miRNA inhibitors. Values are mean \pm s.E.M. $(n=3), * * P<0.01$. (D) The expression of STXBP1 protein in MIN6 cells with knockdown of miR-218 and miR-322.

(E) Immunoflorescence of Stxbp1 in MIN6 cells with overexpression of miR-218 mimics or miR-322 mimics. Scale bars $=50 \mu \mathrm{m}$. (F) The effects of siRNA and the overexpression of miR-218 and miR-322 on insulin secretion ( $n=3, * * P<0.01)$. (G) The knockdown of miR-218 and miR-322 promote insulin secretion of MIN6 cells $(n=3, * * P<0.01)$.

islets cultured with high levels of glucose for a long period (Fig. 5B and Supplementary Figure S2, see section on supplementary data given at the end of this article). Meanwhile, levels of miR-218 and miR-322 were raised to $400 \%$ in islets exposed to $25 \mathrm{mM}$ glucose compared with islets cultured with low levels of glucose. We also determined the expression of syntaxin, which is

Published by Bioscientifica Ltd. 
A
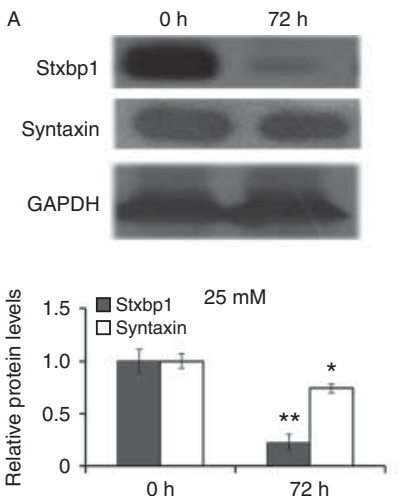

B

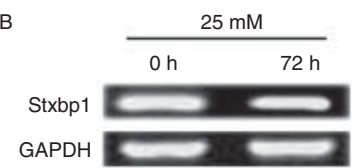

C

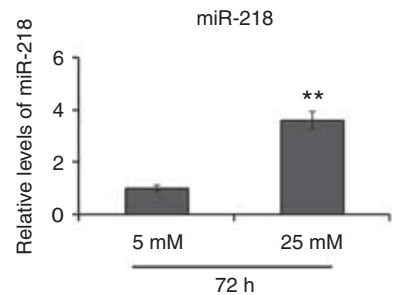

D

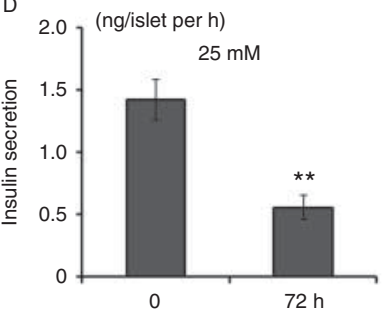

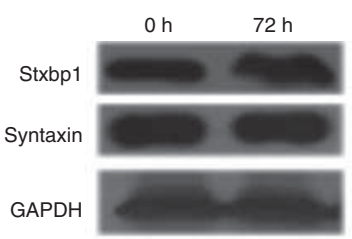
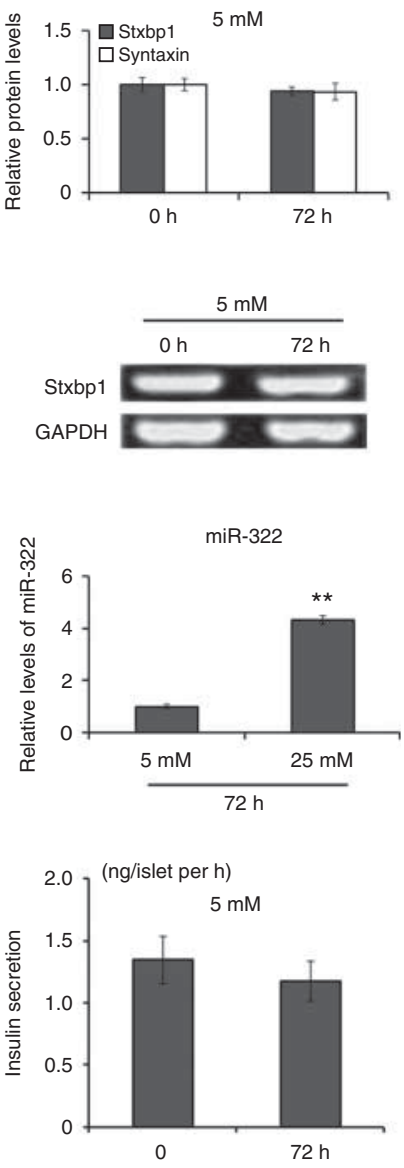

Figure 5

The miR-218/322 co-regulating Stxbp 1 is involved in the $\beta$-cell dysfunction induced by prolonged exposure to high levels of glucose. (A) Western blotting analysis of Stxbp 1 and syntaxin in islets treated with high levels of glucose for $72 \mathrm{~h}$. Islets were cultured in medium containing $25 \mathrm{mM}$ glucose, the $5 \mathrm{mM}$ glucose was used as a negative control. $(n=3, * \star P<0.01$, $* P<0.05)$. (B) PCR analysis of Stxbp1 mRNA in islets incubated with prolonged exposure to high levels of glucose. (C) Effects of long-term high levels of glucose on the expression of miR-218 and miR-322 in mouse islets. (D) The levels of insulin secretion from islets treated with prolonged high levels of glucose $(n=3, * * P<0.01)$.

modulated by Stxbp1 and also involved in insulin secretion, and found that the expression of syntaxin was decreased by $25 \%$ in $\beta$ cells cultured with $25 \mathrm{mM}$ glucose. The levels of insulin secretion of these islets were also determined to evaluate the influence of pro-longed high levels of glucose on $\beta$ cells. As expected, the secreted

insulin was decreased from $1.5 \mathrm{ng} /$ islet per $\mathrm{h}$ to around $0.5 \mathrm{ng} /$ islet per $\mathrm{h}$.

This implied that miR-218 and miR-322 play an important role in the process of $\beta$-cell damage caused by long-term exposure to high levels of glucose.

\section{Discussion}

Although the number of pathways involving miRNAs is continuously increasing, the role of miRNAs in $\beta$-cell function and T2D remains unclear. Recently, miRNAs have been reported to be involved in insulin synthesis, the mechanism still needs further study (Fred et al. 2010, Lu et al. 2010, Wang et al. 2010, Zhao et al. 2010). Although the number of known miRNAs is continuously increasing, information regarding their precise cellular function remains limited. One of the main challenges in understanding the functions of miRNAs is to identify the genuine target genes of miRNAs. In this study, we aimed to identify the novel pathways involving miRNAs and Stxbp1 in the physiological process of insulin secretion.

Although Stxbp1 is well known to participate in the fusion of insulin secretory granules in the plasma membrane of $\beta$ cells (Gomi et al. 2005, Dong et al. 2007, Yu et al. 2014), the expression of Stxbp1 in the process of rapid insulin secretion has not been reported yet. In this study, we determined the expression of both Stxbp1 mRNA and STXBP1 protein during the physiological process of GSIS for the first time, to our knowledge.

Not surprisingly, the protein level of STXBP1 was obviously upregulated in $\beta$ cells, accompanied by increased insulin secretion. However, Stxbp1 mRNA showed little change within 1-h of stimulation, thus it is believed that Stxbp1 expression is regulated at the transcriptional level.

The biological roles of miR-218 and miR-322 have been extensively explored, however, studies focused on their function in $\beta$ cells and T2D were still absent.

By using bioinformatics programs, we selected a group of genuine pairing miRNAs of Stxbp1. We used RT-qPCR to check the expression of these miRNAs in isolated islets cultured in medium containing high levels of glucose, and miR-218 and miR-322 were identified as the candidate regulators of Stxbp1. The two miRNAs were proved to be significantly decreased during the process of rapid GSIS, and the relatively low level of miR-218 and miR-322 may promote the expression of Stxbp1 and insulin secretion.

The subsequent luciferase assays further confirmed that miR-218 and miR-322 directly target the $3^{\prime}$ UTR of Stxbp1. The overexpression of the two miRNAs in MIN6

Published by Bioscientifica Ltd. 
cells leads to the inhibition of Stxbp1 expression and insulin secretion; while the knockdown of the two miRNAs relatively promoted the Stxbp1-insulin pathway.

Glucose has long been recognized as the main stimulator of insulin synthesis and secretion, however, prolonged high levels of glucose, or glucolipotoxicity, decrease insulin secretion, and impair $\beta$-cell function (Eizirik et al. 1992, Conget et al. 1994, Fred et al. 2010). Studies on the molecular mechanism of glucolipotoxicity provide better understanding of T2D. Reduced insulin release has been commonly linked to defective exocytosis. Stxbp1 positively regulates insulin secretion, and it has been reported to be reduced in the islets of both T2D patients and GK rats (Zhang et al. 2002, Lam et al. 2005, Andersson et al. 2012). Our results indicated that the expression levels of miR-218 and miR-322 were raised in mouse islets exposed to high levels of glucose for a long period $(72 \mathrm{~h})$, which is followed by the sharp decrease in expression of Stxbp1 and the blocking of insulin secretion.

In this study, miR-218 and miR-322 were screened out as the upstream regulators of Stxbp1, and played an important role in the process of GSIS. The pathway consisting of miR-218/322 and Stxbp1 was also proved to be involved in $\beta$ cell dysfunction caused by glucolipotoxicity. Therefore, our results contribute to the network consisting of miRNAs, target proteins, and insulin, providing a potential target for studying the molecular mechanisms of $\beta$-cell disorders and diabetes.

\section{Conclusions}

In this study, the pathway consisting of miR-218/322 and Stxbp1 was proved to play an important role in the process of glucose-induced rapid insulin secretion, and was also involved in the $\beta$-cell dysfunction caused by prolonged exposure to high levels of glucose. Stxbp1 significantly promotes insulin secretion, while its expression was regulated by miR-218 and miR-322 in $\beta$ cells.

\section{Supplementary data}

This is linked to the online version of the paper at http://dx.doi.org/10.1530/ JME-14-0305.

\section{Declaration of interest}

The authors declare that there is no conflict of interest that could be perceived as prejudicing the impartiality of the research reported.

\section{Funding}

This study was funded by Applied Basic Research Foundation of Sichuan (2012JY0030)

\section{Author contribution statement}

$\mathrm{H} L$ performed most of the experiments, analyzed data, and wrote the manuscript. $Z A$ and $Z Y$ reviewed and edited the manuscript. $Y W, W G$, and $J X$ performed some experiments. $Z \mathrm{~A}$ and $Z \mathrm{Y}$ contributed to the discussion and edited the manuscript. $X J$ designed the experiments and wrote and edited the manuscript. $X J$ is the guarantor of this work and, as such, had full access to all of the data in the study and takes responsibility for the integrity of the data and the accuracy of the data analysis.

\section{Acknowledgements}

The authors thank Yongjun Luo (Third Military Medical University, Chongqing, China) for technical assistance.

\section{References}

Andersson SA, Olsson AH, Esguerra JL, Heimann E, Ladenvall C, Edlund A, Salehi A, Taneera J, Degerman E, Groop L et al. 2012 Reduced insulin secretion correlates with decreased expression of exocytotic genes in pancreatic islets from patients with type 2 diabetes. Molecular and Cellular Endocrinology 364 36-45. (doi:10.1016/j.mce. 2012.08.009)

Chen CF, Ridzon DA, Broomer AJ, Zhou ZH, Lee DH, Nguyen JT, Barbisin M, Xu NL, Mahuvakar VR, Andersen MR et al. 2005 Real-time quantification of microRNAs by stem-loop RT-PCR. Nucleic Acids Research 33 e179. (doi:10.1093/nar/gni178)

Conget I, Sarri Y, Novials A, Casamitjana R, Vives M \& Gomis R 1994 Functional properties of isolated human pancreatic islets beneficial effects of culture and exposure to high glucose concentrations. Diabète \& Métabolisme 20 99-107.

Del Prato S \& Tiengo A 2001 The importance of first-phase insulin secretion: implications for the therapy of type 2 diabetes mellitus. Diabetes/Metabolism Research and Reviews 17 164-174. (doi:10.1002/ dmrr.198)

Dong Y, Wan Q, Yang X, Bai L \& Xu P 2007 Interaction of Munc18 and Syntaxin in the regulation of insulin secretion. Biochemical and Biophysical Research Communications 360 609-614. (doi:10.1016/j.bbrc. 2007.06.107)

Eizirik DL, Korbutt GS \& Hellerstrom C 1992 Prolonged exposure of human pancreatic islets to high glucose concentrations in vitro impairs the $\beta$-cell function. Journal of Clinical Investigation 90 1263-1268. (doi:10.1172/JCI115989)

Fred RG, Bang-Berthelsen CH, Mandrup-Poulsen T, Grunnet LG \& Welsh N 2010 High glucose suppresses human islet insulin biosynthesis by inducing miR-133a leading to decreased polypyrimidine tract binding protein-expression. PLOS ONE 5 e10843. (doi:10.1371/journal.pone. 0010843)

Gomi H, Mizutani S, Kasai K, Itohara S \& Izumi T 2005 Granuphilin molecularly docks insulin granules to the fusion machinery. Journal of Cell Biology 171 99-109. (doi:10.1083/jcb.200505179)

Hosker JP, Rudenski AS, Burnett MA, Matthews DR \& Turner RC 1989 Similar reduction of first- and second-phase B-cell responses at three different glucose levels in type II diabetes and the effect of gliclazide therapy. Metabolism: Clinical and Experimental 38 767-772. (doi:10.1016/0026-0495(89)90064-4)

Kahn SE 2001 Clinical review 135: the importance of $\beta$-cell failure in the development and progression of type 2 diabetes. Journal of Clinical Endocrinology and Metabolism 86 4047-4058. (doi:10.1210/jcem.86.9. 7713)

Lam PP, Leung YM, Sheu L, Ellis J, Tsushima RG, Osborne LR \& Gaisano HY 2005 Transgenic mouse overexpressing syntaxin-1A as a diabetes model. Diabetes 54 2744-2754. (doi:10.2337/diabetes.54.9.2744) 
Lu H, Buchan RJ \& Cook SA 2010 MicroRNA-223 regulates Glut4 expression and cardiomyocyte glucose metabolism. Cardiovascular Research $\mathbf{8 6}$ 410-420. (doi:10.1093/cvr/cvq010)

Melloul D, Ben-Neriah Y \& Cerasi E 1993 Glucose modulates the binding of an islet-specific factor to a conserved sequence within the rat I and the human insulin promoters. PNAS 90 3865-3869. (doi:10.1073/pnas. 90.9.3865)

Neuman JC, Truchan NA, Joseph JW \& Kimple ME 2014 A method for mouse pancreatic islet isolation and intracellular cAMP determination. Journal of Visualized Experiments e50374. (doi:10.3791/50374)

Pelaez N \& Carthew RW 2012 Biological robustness and the role of microRNAs: a network perspective. Current Topics in Developmental Biology 99 237-255. (doi:10.1016/B978-0-12-387038-4.00009-4)

Sarkar S, Dey BK \& Dutta A 2010 MiR-322/424 and -503 are induced during muscle differentiation and promote cell cycle quiescence and differentiation by down-regulation of Cdc25A. Molecular Biology of the Cell 21 2138-2149. (doi:10.1091/mbc.E10-01-0062)

Schmittgen TD, Jiang J, Liu Q \& Yang L 2004 A high-throughput method to monitor the expression of microRNA precursors. Nucleic Acids Research 32 e43. (doi:10.1093/nar/gnh040)

Shantikumar S, Caporali A \& Emanueli C 2012 Role of microRNAs in diabetes and its cardiovascular complications. Cardiovascular Research 93 583-593. (doi:10.1093/cvr/cvr300)

Sun LL, Jiang BG, Li WT, Zou JJ, Shi YQ \& Liu ZM 2011 MicroRNA-15a positively regulates insulin synthesis by inhibiting uncoupling protein-2 expression. Diabetes Research and Clinical Practice 91 94-100. (doi:10.1016/j.diabres.2010.11.006)

Wang B, Herman-Edelstein M, Koh P, Burns W, Jandeleit-Dahm K, Watson A, Saleem M, Goodall GJ, Twigg SM, Cooper ME et al. 2010 E-cadherin expression is regulated by miR-1921215 by a mechanism that is independent of the profibrotic effects of transforming growth factor- $\beta$. Diabetes 59 1794-1802. (doi:10.2337/ db09-1736)

Xiao ZD, Jiao CY, Huang HT, He LJ, Zhao JJ, Lu ZY \& Liu LX 2014 miR-218 modulate hepatocellular carcinoma cell proliferation through PTEN/AKT/PI3K pathway and HoxA10. International Journal of Clinical and Experimental Pathology 7 4039-4044.

Yu H, Rathore SS, Gulbranson DR \& Shen J 2014 The N- and C-terminal domains of tomosyn play distinct roles in soluble $\mathrm{N}$-ethylmaleimidesensitive factor attachment protein receptor binding and fusion regulation. Journal of Biological Chemistry 289 25571-25580. (doi:10.1074/jbc.M114.591487)

Zhang CY, Baffy G, Perret P, Krauss S, Peroni O, Grujic D, Hagen T, VidalPuig AJ, Boss O, Kim YB et al. 2001 Uncoupling protein-2 negatively regulates insulin secretion and is a major link between obesity, $\beta$ cell dysfunction, and type 2 diabetes. Cell 105 745-755. (doi:10.1016/ S0092-8674(01)00378-6)

Zhang W, Khan A, Ostenson CG, Berggren PO, Efendic S \& Meister B 2002 Down-regulated expression of exocytotic proteins in pancreatic islets of diabetic GK rats. Biochemical and Biophysical Research Communications 291 1038-1044. (doi:10.1006/bbrc.2002.6555)

Zhang H, Yang H, Zhang C, Jing Y, Wang C, Liu C, Zhang R, Wang J, Zhang J, Zen K et al. 2015 Investigation of microRNA expression in human serum during the aging process. Journals of Gerontology. Series A, Biological Sciences and Medical Sciences 70 102-109. (doi:10.1093/gerona/glu145)

Zhao H, Guan J, Lee HM, Sui Y, He L, Siu JJ, Tse PP, Tong PC, Lai FM \& Chan JC 2010 Up-regulated pancreatic tissue microRNA-375 associates with human type 2 diabetes through $\beta$-cell deficit and islet amyloid deposition. Pancreas 39 843-846. (doi:10.1097/MPA. Ob013e3181d12613)

Received in final form 2 December 2014

Accepted 8 December 2014

Accepted Preprint published online 8 December 2014
() 2015 Society for Endocrinology Printed in Great Britain 